\title{
Introduction of the Teaching of Traditional Medicine in Medical Schools in Togo
}

\author{
Essossinam Kpelao ${ }^{1}$, Julienne Noudé Teclessou ${ }^{1}$, Bidamin Ntimon ${ }^{2}$, Essobozou Pegbessou ${ }^{1}$, \\ Saliou Salifou' ${ }^{1}$, Sherif Adjita1 ${ }^{1}$, Abd El Kader Moumouni ${ }^{1}$
}

${ }^{1}$ University of Lomé, Lomé, Togo

${ }^{2}$ University of Kara, Kara, Togo

Email: ^kpelas77@yahoo.fr, tjulie06@yahoo.fr, cntimon@yahoo.fr, pessodina@yahoo.fr, salioubab@yahoo.fr, sadjita@gmail.com, toges3kes@gmail.com

How to cite this paper: Kpelao, E., Teclessou, J. N., Ntimon, B., Pegbessou, E., Salifou, S., Adjita, S., \& El Kader Moumouni, A. (2018). Introduction of the Teaching of Traditional Medicine in Medical Schools in Togo. Creative Education, 9, 633-637. https://doi.org/10.4236/ce.2018.95045

Received: February 11, 2018

Accepted: April 16, 2018

Published: April 19, 2018

Copyright $\odot 2018$ by authors and Scientific Research Publishing Inc. This work is licensed under the Creative Commons Attribution International License (CC BY 4.0).

http://creativecommons.org/licenses/by/4.0/

(c) (i) Open Access

\begin{abstract}
Objectives: The use of traditional medicine is widespread in many countries of the world. A study found that $80 \%$ of rural populations living in developing countries depend on traditional medicine for their health needs. African Traditional Medicine remains poorly documented. However, because of this large attendance by the population, African physicians cannot continue to ignore this fact. The purpose of this study was to conduct a survey among physicians to find out what they think about the introduction of the teaching of ATM in medical schools in Togo. Methods: This is a cross-sectional survey of Togolese physicians over a period of a year, from December $1^{\text {st }}, 2016$ to November $30^{\text {th }}, 2017$. An anonymous questionnaire was sent to them and retrieved after filling. The socio-demographic and the general data on traditional medicine were asked. Results: 276 physicians completed the questionnaire. Their average age was 34.41 years. These physicians exercised mainly in public hospitals (91.3\%). General practitioners were predominant $(67.4 \%)$. The majority $(62.7 \%)$ of the physicians surveyed believed in the existence of the ATM and $57.6 \%$ had at least once witnessed its success. ATM teaching in medical schools was approved by 209 (75.7\%) of the physicians surveyed. Conclusion: The teaching of African traditional medicine in medical schools is widely accepted by the physicians surveyed. The challenges of this teaching are important because of the lack of documentation and resource persons.
\end{abstract}

\section{Keywords}

Traditional Medicine Teaching, Medical Schools, Togo

\section{Introduction}

Traditional medicine (TM) is defined by World Health Organization (WHO), as 
"health practices, approaches, knowledge and beliefs incorporating plant, animal and mineral-based medicines, spiritual therapies, manual techniques and exercises, applied singularly or in combination to maintain well-being, as well as to treat, diagnose or prevent illness" (World Health Organization, 2013). The use of traditional, complementary and alternative medicine is widespread in many countries of the world (Barnes, Powell-Griner, McFann, \& Nahin, 2004; Mak \& Faux, 2009). In Africa, more and more people have been using traditional medicine to treat their ailments, either as a complement or substitute to more bio-medical treatment regimens (Singh, Raidoo, \& Harries, 2004). A study found that $80 \%$ of rural populations living in developing countries depend on traditional medicine for their health needs (Peltzer, Preez, Ramalagan, \& Fomundam, 2008). Other traditional medicines like the Chinese have been able to modernize while keeping their specificity. African Traditional Medicine (ATM) remains poorly documented with practices that are difficult to transpose from one individual to another. However because of this large attendance by the population, African physicians cannot continue to ignore this fact even if the aim of their training is to master the so-called modern medical knowledge. It is thus important to understand this medicine and to recover the best of it to associate to their knowledge. The purpose of this study was to conduct a survey among physicians to find out what they think about the introduction of the teaching of ATM in medical schools in Togo.

\section{Methods}

This is a cross-sectional survey of Togolese physicians over a period of a year, from December $1^{\text {st }}, 2016$ to November $30^{\text {th }}, 2017$. An anonymous questionnaire was sent to them and retrieved after filling. The socio-demographic data (age, year of defense of thesis, specialization ...) and the general data on traditional medicine were asked (existence, efficiency, operating bases, the profile of a traditional therapist) were collected. The opinion of the participants on the introduction of the teaching of ATM in medical schools and the modalities of this teaching was put forward. The data was analyzed with epi-info 7 software.

\section{Results}

A total of 276 physicians completed the questionnaire. The average age of the physicians was 34.41 years $+/-5$ (with extremes of 27 years -56 years) completed the questionnaire. These physicians had obtained their doctoral thesis in medicine between 1989 and 2017 and exercised mainly in public hospitals (91.3\%). General practitioners were predominant (67.4\%) compared to $32.6 \%$ specialists. The majority (62.7\%) of the physicians surveyed believed in the existence of the ATM and $57.6 \%$ had at least once witnessed its success. The diseases in which they were witnessed were: organic (58.5\%), mystical (35.8\%) psychological (25.2\%). According to them, several reasons explain the attendance of traditional healers by the population (Table 1). 
Table 1. The reasons explaining the success of ATM with the population.

\begin{tabular}{ccc}
\hline & Number & Percentage (\%) \\
\hline Poverty of the population & 187 & 67.7 \\
Ignorance of the population & 107 & 38.8 \\
Efficiency & 102 & 37.0 \\
\hline
\end{tabular}

The basics of ATM cited by the respondents were scientific (19.2\%), mystical (27.2\%) or placebo (22.1\%). According to the physicians, the herbalist (62.3\%) corresponded at best to the profile of traditional therapist ahead of the healers (using rituals and incantations) in $12.7 \%$.

ATM teaching in medical schools was approved by $209(75.7 \%)$ of the physicians surveyed. They think that this teaching is possible and useful to the career of a modern physician for reasons summarized in Table 2.

With regards to the evaluation methods, $32.3 \%$ recommend that this teaching be compulsory against $48.9 \%$ who want it optional. This teaching will modernize (scientific rigor) the ATM (93.1\%). Nearly $8 \%$ of the physicians surveyed believe that ATM is harmful and must be combated.

\section{Discussion}

African Traditional Medicine is very popular in Africa (Barnes et al., 2004; Gqaleni, Moodley, Kruger, Ntuli, \& McLeod, 2007). Several factors explain this high attendance, namely, isolation, inaccessibility of health structures, poverty and for its effectiveness (World Health Organization, 2013; Kim, 2012; Labhardt et al., 2010). Hollenbergstressed TM was continuously being neglected by medical schools despite evidence of its significant influence within African countries (Hollenberg, Zakus, Cook, \& Wei, 2008). But this global increase in demand for alternativemedicine has led some medical schools in Western and many Asian countries to incorporate TM into their curricula (Fenton \& Morris, 2003). Hence $85 \%$ of Korean, $77 \%$ of Canadian and $20 \%$ of Japan medical schools taught alternative medicine (Kim, 2012). In South Africa, only one medical school is taught traditional medicine practically (Chitindingu et al., 2014). The majority of physicians in our survey (75.7\%) believe that their teaching in medical schools will be useful in the exercise of their profession in Africa for several reasons. First, access to ancestral knowledge of plant virtues by herbalists (which best corresponds to the definition of a traditional therapist) can be exploited as a source of research (40.5\%). This is hardly surprising, as most of the drugs used in modern medicine come from plants. Another reason is that it will help them to understand the psychological and sociocultural characteristics of the populations in the environment in which they provide care. Indeed, because of the cultural weight, the majority of African populations has a different conception of the evils from which they suffer. The origin of certain diseases for the majority still remains mystical, supernatural, as result of a bad spell or linked to a 
Table 2. Reasons explaining the usefulness of ATM teaching in medical schools according to the physicians that completed the survey.

\begin{tabular}{ccc}
\hline & Number & Percentage (\%) \\
\hline Sources of research for modern medicine & 85 & 40.5 \\
Diversity of knowledge & 62 & 29.7 \\
ATM is closer to african realities & 34 & 16.2 \\
Promote the ATM & 17 & 8.1 \\
Affordable cost for the population & 11 & 5.4 \\
Total & $\mathbf{2 0 9}$ & $\mathbf{1 0 0}$ \\
\hline
\end{tabular}

transgression of a social prohibition. Traditional medicine can find solutions to these problems. Like modern medicine, the ATM is passed down from generation to generation or after initiation with a mentor. Which means that there is some knowledge that its practitioners hold. The main problem lies in the practical organization of this teaching with regard to the choice of resource persons and the determination of the educational program because it is an informal sector, little documented, made of individual practices as diverse as varied. The challenge of incorporating alternative medicine into biomedical curriculums was noted by Kim (Kim, 2012) who suggested that introducing new content faces many barriers including "a lack of an evidence-based approach, insufficiently reliable reference resources, and insufficient time to incorporate new courses". Medical schools are therefore often resistance to fully incorporate alternative medecine due to curriculum overload or lack of adequate resources for its incorporation (Gqaleni et al., 2007). As a possible solution, we can rely on the association of traditional healers who will certify these members on the basis of the rules of ethics and efficiency practices that have already been the subject of a procedure established by the administrative authorities and the scientific community. These certified persons will be able to form the basis of the lecturers. The choice of the lecturer will be made only after validation by a scientific and ethical committee (including physicians, pharmacists, biologists, politicians, traditional healers, representatives of the patients association). To adjust the time constraints, this optional teaching can be made as suggested by $48.9 \%$ of the participants. The challenges of this teaching are enormous but not insurmountable. Difficulties often generate solutions, as some authors have pointed out: when teaching health subjects, a problem-based approach is optimal as students are provided an opportunity gain practical experience through problem-solving. They further stress that problem solving skills are the most important skills to acquire rather than memory skill only (Barrows \& Tamblyn, 1980). Whether compulsory or not, the most important is to have notions of traditional medicine that will allow to modernize (93.1\%) and promote it.

\section{Conclusion}

The teaching of African traditional medicine in medical schools is widely ac- 
cepted by the physicians surveyed. The challenges of this teaching are important because of the lack of documentation and resource persons. It will allow future physicians to be better equipped in certain situations. This teaching will also help demystify and authenticate ATM best practices and at the same time provide a foundation for research fields to enrich modern medicine.

\section{Conflict of Interest}

The authors declare that they have no conflict of interest.

\section{References}

Barnes, P. M., Powell-Griner, E., McFann, K., \& Nahin, R. L. (2004). Complementary and Alternative Medicine Use among Adults: United States, 2002. Seminars in Integrative Medicine, 2, 54-71. https://doi.org/10.1016/j.sigm.2004.07.003

Barrows, H. S., \& Tamblyn, R. M. (1980). Problem Based Learning: An Approach to Medical Education. New York: Springer Publishing Company.

Chitindingu, E., George, G., \& Gow, J. (2014). A Review of the Integration of Traditional, Complementary and Alternative Medicine into the Curriculum of South African Medical Schools. BMC Medical Education, 14, 40. https://doi.org/10.1186/1472-6920-14-40

Fenton, M. V., \& Morris, D. L. (2003). The Integration of Holistic Nursing Practices and Complementary and Alternative Modalities into Curricula of Schools of Nursing. Alternative Therapies in Health and Medicine, 9, 62-67.

Gqaleni, N., Moodley, I., Kruger, H., Ntuli, A., \& McLeod, H. (2007). Traditional and Complementary Medicine. South African Health Review, 12, 175-188.

Hollenberg, D., Zakus, D., Cook, T., \& Wei, X. (2008). Re-Positioning the Role of Traditional, Complementary and Alternative Medicine as Essential Health Knowledge in Global Health: Do They Still Have a Role to Play? World Health \& Population, 10, 62-75.

Kim, D. Y., Park, W. B., Kang, H. C., Kim, M. J., Park, K. H., Min, B., Suh, D., Lee, H. W., Jung, S. P., Chun, M., \& Lee, S. N. (2012). Complementary and Alternative Medicine in the Undergraduate Medical Curriculum: A Survey of Korean Medical Schools. Journal of Alternative and Complementary Medicine, 18, 870-874.

https://doi.org/10.1089/acm.2011.0179

Labhardt, N. D., Aboa, S. M., Manga, E., Bensing, J. M., \& Langewitz, W. (2010). Bridging the Gap: How Traditional Healers Interact with Their Patients. A Comparative Study in Cameroon. Tropical Medicine \& International Health, 15, 1099-1108.

Mak, J. C., \& Faux, S. (2009). Complementary and Alternative Medicine Use by Osteoporotic Patients in Australia (CAMEO-a): A Prospective Study. Journal of Alternative and Complementary Medicine, 16, 579-584. https://doi.org/10.1089/acm.2009.0425

Peltzer, K., Preez, N. F., Ramalagan, S., \& Fomundam, H. (2008). Use of Traditional Complementary and Alternative Medicine for HIV Patients in KwaZulu-Natal, South Africa. BMC Public Health, 8, 255. https://doi.org/10.1186/1471-2458-8-255

Singh, V., Raidoo, D. M., \& Harries, C. S. (2004). The Prevalence, Patterns of Usage and People's Attitude towards Complementary and Alternative Medicine (CAM) among the Indian Community in Chatsworth, South Africa. BMC Complementary and Alternative Medicine, 4, 3-7. https://doi.org/10.1186/1472-6882-4-3

World Health Organization (2013). Factsheet 134: Traditional Medicine. Geneva: World Health Organization. http://www.who.int/mediacentre/factsheets/2003/fs134/en/ 